\title{
Expression Analysis of Aquaporin-1 (Aqp-1) in Human Biliary Tract Carcinoma
}

\author{
Shinichi Sekine*, Tomoyuki Okumura, Takuya Nagata, Kazuto Shibuya, Isaku Yoshioka, \\ Koshi Matsui, Ryouta Hori, Kazuhiro Tsukada \\ Department of Surgery and Science, University of Toyama, Toyama, Japan \\ Email: *sekky@med.u-toyama.ac.jp
}

Received 23 November 2015; accepted 9 January 2016; published 12 January 2016

Copyright (C) 2016 by authors and Scientific Research Publishing Inc.

This work is licensed under the Creative Commons Attribution International License (CC BY). http://creativecommons.org/licenses/by/4.0/

c) (i) Open Access

\begin{abstract}
Background: Aquaporins (AQPs) are important in controlling bile water secretion. AQP is related to the invasion and metastasis of cancer. However, the relationship of biliary tract cancer is not clear. The role of AQP-1 in cancer cell is also unknown. Methhods: We analyzed AQP-1 expression using tissue microarray (TMA) in 99 samples immunohistochemically (50 gallbladder carcinoma, 39 bile duct carcinoma and 10 Papilla Vater carcinoma patients who underwent surgery at our department from 1997 to 2011). Gene expressions were evaluated by the combination of the immunohistological intensity and distribution. The expression level is compared to the clinico-pathological data of the patients. Results: In the TMA, depth of tumor invasion and histological type are associated with AQP-1 expression. The group of patients with high AQP-1 expression is associated with higher rates of disease specific survival (log-rank $p=0.013)$. Cox's proportional hazard model reveals that $A Q P-1$ expression is an independent prognostic factor $(R R, 0.324 ; p=0.001)$ in multivariate analysis. There is a correlation between AQP-1 expression and tumor invasion. Conclusions: These observations of this study suggest that AQP-1 expression may be favorable biomarkers associated with prognosis and tumor invasion in biliary tract carcinoma.
\end{abstract}

\section{Keywords}

Aquaporin, Biliary Tract Carcinoma, Tissue Microarray, Immunohistochemistry

\section{Introduction}

Biliary tract carcinoma (BTC) is composed of mutated epithelial cells that originate in the bile ducts, which drain bile from the liver into the small intestine. BTC includes carcinomas of the bile duct, gallbladder, and pa-

\footnotetext{
*Corresponding author.
}

How to cite this paper: Sekine, S., Okumura, T., Nagata, T., Shibuya, K., Yoshioka, I., Matsui, K., Hori, R. and Tsukada, K. (2016) Expression Analysis of Aquaporin-1 (Aqp-1) in Human Biliary Tract Carcinoma. Journal of Cancer Therapy, 7, 17-23. 
pilla of Vater. Most patients with BTC present at an advanced disease stage; thus, prognosis remains poor despite the recent development of new diagnostic modalities [1] [2]. Currently, there is no consensus on a universal measure of BTC malignancy; therefore, it is necessary to identify prognostic factors indicating the biological properties of this disease.

Aquaporins (AQPs) are integral membrane proteins that facilitate the movement of water and play important roles in the control of bile formation. However, the exact role of AQPs in human biliary tract carcinogenesis has not been defined [3]-[5]. AQP-1 and AQP-4 have also been implicated in the absorption of water by the intrahepatic bile duct [6] [7]. Epithelial cells of the human and mouse gallbladder express AQP-1 and AQP-8 [8] [9], with AQP-1 localized on both the apical and basolateral plasma membranes of epithelial cells lining the neck of the organ [8]. In addition, AQPs are reportedly distributed within cells lining the mammalian biliary tract [8] [9].

\section{Methods}

We analyzed AQP-1 expression in BTC using tissue microarray (TMA) and identified correlations among the clinicopathological parameters, and patient survival. In this study, we assessed paraffin-embedded tissues of 99 BTC samples (50, 39, and 10 from gall bladders, bile ducts, and papilla of Vater, respectively) collected from patients who had undergone surgery from 1997 to 2011 at Toyama University Hospital (Toyama, Japan). This study was approved by the Ethics Committee, University of Toyama. All samples were histologically diagnosed at the Department of Pathology. The final stage of BTC was pathologically confirmed, according to the TNM classification system of malignant tumors by the Union for International Cancer Control (seventh edition). CEA, CA19-9, tissue type one by each one cases, was not able to confirm the inspection data. Expression profiles of AQP-1 were analyzed using the TMA, as described previously [10] [11]. The protein expression profiles were evaluated by combining immunohistological intensity and distribution. Selected micrographs from the TMAs immunostained with polyclonal antibodies against AQP-1 are shown in Figure 1. The following primary antibodies were used: rabbit polyclonal anti-AQP-1 (H-55: dilution, 1:100; Santa Cruz Biotech, Santa Cruz, CA, USA). Goat anti-rabbit horseradish peroxidase-conjugated immunoglobulin-G was used as a secondary antibody, according to the manufacturer's instructions. The secondary antibodies were visualized using En Vision ${ }^{\mathrm{TM}}+$ Dual Link, Single Reagent (K4061; Dako, Tokyo, Japan), according to the manufacturer's instructions. The staining intensity of carcinoma cells was scored on a 4-point scale: $0=$ no staining of carcinoma cells, $1=$ weak staining, 2 = moderate staining, and $3=$ marked staining, as compared to the staining of control tissues. The staining distribution within the tumor cells was graded on a 3-point scale: $0: n \leq 10 \% ; 1: 10 \% \leq n<50 \%$; and 2: $n \geq 50 \%$. AQP-1 expression in the carcinoma tissue was defined as positive when the sum total of the staining intensity and distribution was graded at a score of $\geq 3$ (Figure 1). Using the Ki67 (MIB-1)-labeling index, the malignancy grade of BTC was rated on a 2-point scale ( $\leq 10$ and $>10 \%)$.

Statistical analysis was performed using the chi-square test and $t$-tests. Prognostic factors were examined by both univariate and multivariate analyses. Survival curves were estimated using the Kaplan-Meier method and differences between survival curves were analyzed using the log-rank test. Multivariate analyses were performed using the Cox proportional hazards model to assess the risk of cancer death. A $p$ value of $<0.05$ was considered statistically significant. All statistical analyses were performed using JMP software for Windows (SAS Institute Inc., Cary, NC, USA).

\section{Results}

The clinicopathological backgrounds and univariate analysis of factors related to survival in patients with BTC

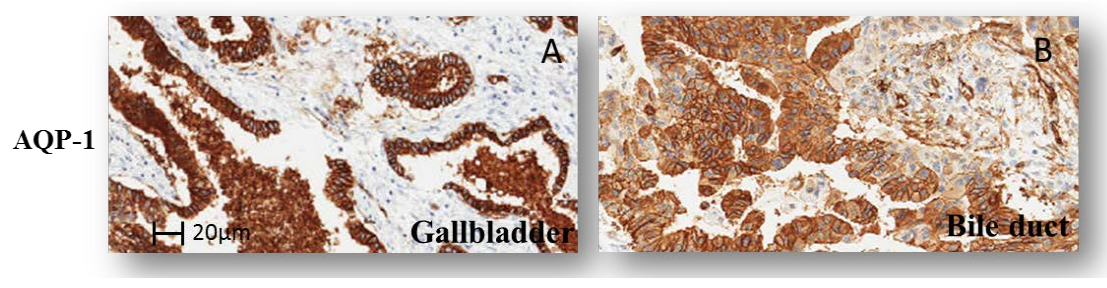

Figure 1. Immunohistochemistry of AQP-1. 
are shown in Table 1. Depth of tumor invasion, lymph node metastasis, distant metastasis, histological type, CEA and CA19-9 were associated with prognosis. AQP-1 expression was also associated with disease-specificsurvival $(p=0.001)$.

Correlations between patient characteristics and expression patterns of AQP-1 in BTC are shown in Table 2. TMA analysis of the 99 tissue samples showed that AQP-1 expression was significantly associated with depth of tumor invasion and histological type ( $p=0.021$ and 0.005$)$. Kaplan-Meier analysis revealed that the group of patients with high AQP-1 expression were associated with higher rates of disease specific survival (log-rank test,

Table 1. Univariate analysis of factors related to survival in patients with biliary tract carcinoma.

\begin{tabular}{|c|c|c|c|c|}
\hline \multirow{2}{*}{ Terms } & \multirow{2}{*}{ Number } & \multirow{2}{*}{$\%$} & \multirow{2}{*}{ Patients alive at 5years (\%) } & \multirow{2}{*}{$\begin{array}{c}p \\
\text { Value }\end{array}$} \\
\hline & & & & \\
\hline \multicolumn{5}{|l|}{ Age (years) } \\
\hline$\geqq 75$ years & 33 & 33.3 & 50.7 & 0.203 \\
\hline$<75$ years & 66 & 66.7 & 39.4 & \\
\hline \multicolumn{5}{|l|}{ Gender } \\
\hline Female & 57 & 57.6 & 46.7 & 0.691 \\
\hline Male & 42 & 42.4 & 38.5 & \\
\hline \multicolumn{5}{|l|}{ Organ } \\
\hline Gallbladder & 50 & 50.5 & 41.5 & 0.249 \\
\hline Bile duct & 39 & 39.4 & 37.2 & \\
\hline Papilla vater & 10 & 10.1 & 70 & \\
\hline \multicolumn{5}{|l|}{ Depth of tumor invasion } \\
\hline $\mathrm{T} 1 / \mathrm{T} 2$ & 48 & 48.5 & 68.2 & $<0.001^{* *}$ \\
\hline $\mathrm{T} 3 / \mathrm{T} 4$ & 51 & 51.5 & 15.4 & \\
\hline \multicolumn{5}{|l|}{ Lymph node metastasis } \\
\hline Absent & 51 & 51.5 & 68.7 & $<0.001^{* *}$ \\
\hline Present & 48 & 48.5 & 14.6 & \\
\hline \multicolumn{5}{|l|}{ Distant metastasis } \\
\hline Absent & 76 & 76.8 & 56.0 & $<0.001^{* *}$ \\
\hline Present & 23 & 23.2 & 0.0 & \\
\hline \multicolumn{5}{|l|}{ Histlogical type } \\
\hline Pap/well/moderate & 77 & 78.6 & 51.4 & $<0.001^{* *}$ \\
\hline Poor/others & 21 & 21.4 & 15.2 & \\
\hline \multicolumn{5}{|l|}{ CEA (ng/ml) } \\
\hline$\leqq 5$ & 75 & 76.5 & 51.8 & $<0.001^{* *}$ \\
\hline$>5$ & 23 & 23.5 & 11 & \\
\hline \multicolumn{5}{|l|}{ CA19-9 (U/ml) } \\
\hline$\leqq 37$ & 55 & 56.1 & 51.8 & $0.021^{*}$ \\
\hline$>37$ & 43 & 43.9 & 31.1 & \\
\hline \multicolumn{5}{|l|}{ MIB-1 Index } \\
\hline$\leqq 10 \%$ & 40 & 40.4 & 41.6 & 0.701 \\
\hline$>10 \%$ & 59 & 59.6 & 45.6 & \\
\hline \multicolumn{5}{|l|}{ AQP-1 } \\
\hline Positive & 44 & 44.4 & 61.6 & $\mathrm{0.001}^{* *}$ \\
\hline Negative & 55 & 55.6 & 27.6 & \\
\hline
\end{tabular}

${ }^{*}: p<0.05 ;{ }^{* *}: p<0.01$. 
Table 2. Relationship between patient characteristics and AQP-1.

\begin{tabular}{|c|c|c|c|c|}
\hline \multirow{3}{*}{ Terms } & \multirow{3}{*}{ N (\%) } & \multicolumn{2}{|c|}{ AQP-1 expression } & \multirow{3}{*}{$p$} \\
\hline & & Positive & Negative & \\
\hline & & $(n=44)$ & $(n=55)$ & \\
\hline \multicolumn{5}{|l|}{ Age (years) } \\
\hline$\geqq 75$ years & 33 & 18 & 15 & \\
\hline$<75$ years & 66 & 26 & 40 & 0.153 \\
\hline \multicolumn{5}{|l|}{ Gender } \\
\hline Female & 57 & 29 & 28 & \\
\hline Male & 42 & 15 & 27 & 0.132 \\
\hline \multicolumn{5}{|l|}{ Organ } \\
\hline Gallbladder & 50 & 24 & 26 & \\
\hline Bile duct & 39 & 14 & 25 & \\
\hline Ampullary & 10 & 6 & 4 & 0.301 \\
\hline \multicolumn{5}{|l|}{ Depth of tumor invasion } \\
\hline $\mathrm{T} 1-\mathrm{T} 2$ & 48 & 27 & 21 & \\
\hline T3-T4 & 51 & 17 & 34 & $0.021^{*}$ \\
\hline \multicolumn{5}{|l|}{ Lymph node metastasis } \\
\hline Negatie & 51 & 25 & 26 & \\
\hline Positive & 48 & 19 & 29 & 0.345 \\
\hline \multicolumn{5}{|l|}{ Distant metastasis } \\
\hline Negatie & 76 & 37 & 39 & \\
\hline Positive & 23 & 7 & 16 & 0.118 \\
\hline \multicolumn{5}{|l|}{ Histrogical type } \\
\hline Pap/well/moderate & 77 & 40 & 37 & \\
\hline Poor/others & 21 & 4 & 17 & $0.005^{* *}$ \\
\hline \multicolumn{5}{|l|}{ CEA (ng/ml) } \\
\hline$\geqq 5$ & 23 & 8 & 15 & \\
\hline$<5$ & 75 & 36 & 39 & 0.261 \\
\hline \multicolumn{5}{|l|}{ CA19-9 (U/ml) } \\
\hline$\geqq 37$ & 43 & 16 & 27 & \\
\hline$<37$ & 55 & 28 & 27 & 0.175 \\
\hline \multicolumn{5}{|l|}{ MIB-1 index } \\
\hline$\leqq 10 \%$ & 59 & 22 & 37 & \\
\hline$>10 \%$ & 40 & 22 & 18 & 0.082 \\
\hline
\end{tabular}

$\stackrel{*}{:} p<0.05 ;{ }^{* *}: p<0.01$.

$p=0.013$ ) (Figure 2). Cox's proportional hazard model revealed that AQP-1 expression was an independent prognostic factor ( $\mathrm{RR}, 0.324 ; p=0.001)$ in multivariate analysis (Table 3 ). Multivariate analysis showed that Lymph node metastasis, Distant metastasis and CEA ( $p=0.035,<0.001$ and 0.027$)$ were also associated with survival (Table 3).

\section{Discussion}

AQP-1 plays an important role in bile formation across cell membranes of the biliary epithelium [5] [12] [13]. Recently, various studies have focused on the association of AQPs with carcinoma and reported that several types of cancer express AQP-1, which may be involved in carcinogenesis and tumor progression [14]-[19]. 


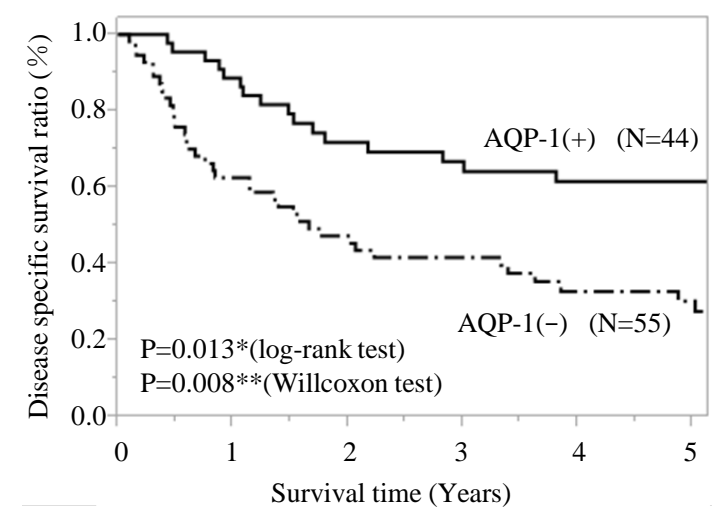

Figure 2. Survival rates of BTC patients with the AQP-1 expression.

Table 3. Relationship between patient characteristics and prognosis in biliary tract carcinoma. (Multivariate analysis).

\begin{tabular}{|c|c|c|c|c|}
\hline Patient characteristics & RR & $95 \%$ CI & $p$ value & \\
\hline Age ( $\geqq 75$ years) & 1.002 & $(0.429-2.239)$ & 0.996 & \\
\hline Sex (male) & 1.709 & $(0.885-3.312)$ & 0.11 & \\
\hline Depth of tumor invasion (T1/T2) & 0.448 & $(0.1807-1.056)$ & 0.067 & \\
\hline Lymph node metastasis (present) & 2.309 & $(1.058-5.218)$ & 0.035 & * \\
\hline Distant metastasis (present) & 11.27 & $(3.808-34.79)$ & $<0.001$ & * * \\
\hline Historical Type (pap/well/moderate) & 0.385 & $(0.173-0.891)$ & 0.027 & * \\
\hline $\mathrm{CEA}(\geqq 5)$ & 1.875 & $(0.780-4.574)$ & 0.161 & \\
\hline CA19-9 $(\geqq 5)$ & 0.839 & $(0.447-1.554)$ & 0.577 & \\
\hline AQP-1 (positive) & 0.324 & $(0.155-0.650)$ & 0.001 & ** \\
\hline
\end{tabular}

${ }^{*}: p<0.05 ;{ }^{* *}: p<0.01$.

These observations suggested a potential role of AQP-1 in BTC. There was no difference in AQP-1 expression between carcinomas of the gallbladder, bile duct carcinoma, and papilla of Vater. AQP-1 is expressed in the biliary epithelium and its expression decreases with the degree of invasion of the carcinoma. This conclusion is also evident in the literature [20].

AQPs are distributed in the pancreas and biliary tract and are essential for secretion and reabsorption of water in the bile and pancreatic juice. AQP-1 is strongly expressed in the intercalated ducts in humans and maintains cellular integrity to protect tissues against cancer cell invasion [6] [13].

Overexpression of AQP-1 was associated with increased proliferation and migration in colorectal and nonsmall cell lung carcinomas. The results of this study suggested that AQP-1 plays a different role in BTC, such as facilitation of bile transport and reabsorption. The roles of the biliary epithelium in BTC differ from those in cancers of the colon and lung [17]-[19]. Therefore, AQP-1 expression in BTC may be an indicator of tumor cell invasion and proliferation associated with carcinoma progression.

Epithelium-mesenchyme transition (EMT) is a specialized mechanism in which the character of the tissue is undifferentiated. Previous studies have suggested that EMT through AQPs greatly contributes to regulation of malignancy [21]. Involvement in the invasion and metastasis of a hypercoagulable state of adenocarcinoma through loss of cell-cell adhesion is mediated by the loss of AQP-1 function. The activation of molecules related to epithelial stromal migration and cell proliferation has been suggested. Bordering on this stage, there exists the possibility for acceleration of metastatic potential. Controlling AQP-1 may contribute to prognosis extension in BTC.

\section{Conclusion}

These observations of this study suggest that AQP-1 expression may be favorable biomarkers associated with 
prognosis and tumor invasion in biliary tract carcinoma.

\section{Acknowledgements}

This study was supported by KAKENHI Grant-in-Aid for Research Activity Start-up from the Ministry of Education, Culture, Sports, Science and Technology of Japan.

\section{References}

[1] Miyakawa, S., Ishihara, S., Horiguchi, A., et al. (2009) Biliary Tract Cancer Treatment: 5584 Results from the Biliary Tract Cancer Statistics Registry from 1998 to 2004 in Japan. Journal of Hepato-Biliary-Pancreatic Surgery, 16, 1-7. http://dx.doi.org/10.1007/s00534-008-0015-0

[2] Tsukada, K., Hatakeyama, K., Kurosaki, I., et al. (1996) Outcome of Radical Surgery for Carcinoma of the Gallbladder According to the TNM Stage. Surgery, 120, 816-821. http://dx.doi.org/10.1016/S0039-6060(96)80089-4

[3] Verkman, A.S. and Mitra, A.K. (2000) Structure and Function of Aquaporin Water Channels. Am J Physiol Renal Physiol, 278, F13-F28.

[4] Brown, D., Katsura, T., Kawashima, M., et al. (1995) Cellular Distribution of the Aquaporins: A Family of Water Channel Proteins. Histochemistry and Cell Biology, 104, 1-9. http://dx.doi.org/10.1007/BF01464780

[5] Mobasheri, A. and Marples, D. (2004) Expression of the AQP-1 Water Channel in Normal Human Tissues: A Semiquantitative Study Using Tissue Microarray Technology. American Journal of Physiology—Cell Physiology, 286, C529-C537. http://dx.doi.org/10.1152/ajpcell.00408.2003

[6] Portincasa, P., Palasciano, G., Svelto, M. and Calamita, G. (2008) Aquaporins in the Hepatobiliary Tract. Which, Where and What They Do in Health and Disease. European Journal of Clinical Investigation, 38, 1-10. http://dx.doi.org/10.1111/j.1365-2362.2007.01897.x

[7] Masyuk, A.I., Gong, A.Y., Kip, S., et al. (2000) Perfused Rat Intrahepatic Bile Ducts Secrete and Absorb Water, Solute, and Ions. Gastroenterology, 119, 1672-1680. http://dx.doi.org/10.1053/gast.2000.20248

[8] Nielsen, S., Smith, B.L., Christensen, E.I. and Agre, P. (1993) Distribution of the Aquaporin CHIP in Secretory and Resorptive Epithelia and Capillary Endothelia. Proceedings of the National Academy of Sciences of the United States of America, 90, 7275-7279. http://dx.doi.org/10.1073/pnas.90.15.7275

[9] Calamita, G., Ferri, D., Bazzini, C., et al. (2005) Expression and Subcellular Localization of the AQP8 and AQP1 Water Channels in the Mouse Gall-Bladder Epithelium. Biology of the Cell, 97, 415-423. http://dx.doi.org/10.1042/BC20040137

[10] Sekine, S., Shimada, Y., Nagata, T., et al. (2012) Prognostic Significance of Aquaporins in Human Biliary Tract Carcinoma. Oncology Reports, 27, 1741-1747. http://dx.doi.org/10.3892/or.2012.1747

[11] Fukuoka, J., Fujii, T., Shih, J.H., et al. (2004) Chromatin Remodeling Factors and BRM/BRG1 Expression as Prognostic Indicators in Non-Small Cell Lung Cancer. Clinical Cancer Research, 10, 4314-4324. http://dx.doi.org/10.1158/1078-0432.CCR-03-0489

[12] Saadoun, S., Papadopoulos, M.C., Hara-Chikuma, M. and Verkman, A.S. (2005) Impairment of Angiogenesis and Cell Migration by Targeted Aquaporin-1 Gene Disruption. Nature, 434, 786-792. http://dx.doi.org/10.1038/nature03460

[13] Masyuk, A.I. and La Russo, N.F. (2006) Aquaporins in the Hepatobiliary System. Hepatology, 43, S75-S81. http://dx.doi.org/10.1002/hep.20996

[14] Moon, C., Soria, J.C., Jang, S.J., et al. (2003) Involvement of Aquaporins in Colorectal Carcinogenesis. Oncogene, 22, 6699-6703. http://dx.doi.org/10.1038/sj.onc.1206762

[15] Jiang, Y. (2009) Aquaporin-1 Activity of Plasma Membrane Affects HT20 Colon Cancer Cell Migration. IUBMB Life, 61, 1001-1009. http://dx.doi.org/10.1002/iub.243

[16] Hu, J. and Verkman, A.S. (2006) Increased Migration and Metastatic Potential of Tumor Cells Expressing Aquaporin Water Channels. FASEB Journal, 20, 1892-1894. http://dx.doi.org/10.1096/fj.06-5930fje

[17] Machida, Y., Ueda, Y., Shimasaki, M., et al. (2011) Relationship of Aquaporin 1, 3, and 5 Expression in Lung Cancer Cells to Cellular Differentiation, Invasive Growth, and Metastasis Potential. Human Pathology, 42, 669-678. http://dx.doi.org/10.1016/j.humpath.2010.07.022

[18] Bin, K. and Zhao, S.-P. (2011) Acetazolamide Inhibits Aquaporin-1 Expression and Colon Cancer Xenograft Tumor Growth. Hepatogastroenterology, 58, 1502-1506. http://dx.doi.org/10.5754/hge11154

[19] Yoshida, T., Hojo, S., Sekine, S., et al. (2013) Expression of Aquaporin-1 Is a Poor Prognostic Factor for Stage II and III Colon Cancer. Molecular and Clinical Oncology, 1, 953-958. http://dx.doi.org/10.3892/mco.2013.165 
[20] Aishima, S., Kuroda, Y., Nishihara, Y., et al. (2007) Down-Regulation of Aquaporin-1 in Intrahepatic Cholangiocarcinoma Is Related to Tumor Progression and Mucin Expression. Human Pathology, 38, 1819-1825. http://dx.doi.org/10.1016/j.humpath.2007.04.016

[21] Nath, S. and Mukherjee, P. (2014) MUC1: A Multifaceted Oncoprotein with a Key Role in Cancer Progression. Trends in Molecular Medicine, 20, 332-342. http://dx.doi.org/10.1016/j.molmed.2014.02.007 